\title{
Prevalence and phylogenetic analysis of hepatitis E virus in pigs, wild boars, roe deer, red deer and moose in Lithuania
}

\author{
Ugne Spancerniene ${ }^{1 *} \mathbb{0}$, Juozas Grigas ${ }^{1}$, Jurate Buitkuviene ${ }^{2}$, Judita Zymantiene ${ }^{1}$, Vida Juozaitiene ${ }^{3}$, \\ Milda Stankeviciute ${ }^{4}$, Dainius Razukevicius ${ }^{4}$, Dainius Zienius ${ }^{5}$ and Arunas Stankevicius ${ }^{1}$
}

\begin{abstract}
Background: Hepatitis E virus (HEV) is one of the major causes of acute viral hepatitis worldwide. In Europe, foodborne zoonotic transmission of HEV genotype 3 has been associated with domestic pigs and wild boar. Controversial data are available on the circulation of the virus in animals that are used for human consumption, and to date, no gold standard has yet been defined for the diagnosis of HEV-associated hepatitis. To investigate the current HEV infection status in Lithuanian pigs and wild ungulates, the presence of viral RNA was analyzed by nested reverse transcription polymerase chain reaction (RT-nPCR) in randomly selected samples, and the viral RNA was subsequently genotyped.

Results: In total, 32.98 and $22.55 \%$ of the domestic pig samples were HEV-positive using RT-nPCR targeting the ORF1 and ORF2 fragments, respectively. Among ungulates, 25.94\% of the wild boar samples, 22.58\% of the roe deer samples, $6.67 \%$ of the red deer samples and $7.69 \%$ of the moose samples were positive for HEV RNA using primers targeting the ORF1 fragment. Using primers targeting the ORF2 fragment of the HEV genome, viral RNA was only detected in $17.03 \%$ of the wild boar samples and $12.90 \%$ of the roe deer samples. Phylogenetic analysis based on a 348-nucleotide-long region of the HEV ORF2 showed that all obtained sequences detected in Lithuanian domestic pigs and wildlife belonged to genotype 3. In this study, the sequences identified from pigs, wild boars and roe deer clustered within the $3 i$ subtype reference sequences from the GenBank database. The sequences obtained from pig farms located in two different counties of Lithuania were of the HEV $3 f$ subtype. The wild boar sequences clustered within subtypes $3 \mathrm{i}$ and $3 \mathrm{~h}$, clearly indicating that wild boars can harbor additional subtypes of HEV. For the first time, the ORF2 nucleotide sequences obtained from roe deer proved that HEV subtype 3i can be found in a novel host.
\end{abstract}

Conclusion: The results of the viral prevalence and phylogenetic analyses clearly demonstrated viral infection in Lithuanian pigs and wild ungulates, thus highlighting a significant concern for zoonotic virus transmission through both the food chain and direct contact with animals. Unexpected HEV genotype 3 subtype diversity in Lithuania and neighboring countries revealed that further studies are necessary to understand the mode of HEV transmission between animals and humans in the Baltic States region.

Keywords: Moose, ORF2, Phylogenetic analysis, Pig, Red deer, Roe deer, Wild boar

\section{Background}

Hepatitis E virus (HEV) which causes a food and water borne disease in humans [1], has emerged during the past decade as a causative agent of autochthonous hepatitis in

\footnotetext{
${ }^{*}$ Correspondence: ugne.spancerniene@lsmuni.lt

${ }^{1}$ Department of Anatomy and Physiology, Faculty of Veterinary Medicine, Lithuanian University of Health Sciences, Tilzes str. 18, Kaunas, Lithuania Full list of author information is available at the end of the article
}

developed countries [2]. Meat and meat-derived products from HEV-infected reservoir animals can transmit the virus to humans and represent a public health concern [3]. The first evidence of the zoonotic transmission of HEV genotype 3 was found in Japan in 2003, when several cases of hepatitis $E$ infection were linked to the consumption of pig and deer meat or organs $[4,5]$. More case reports (grilled wild boar meat in Japan, pig meat in 
Spain, figatelli sausage from Corsica) have provided additional evidence that HEV is a zoonosis that can be transmitted via the consumption of contaminated food [6-8]. Admittedly, known viral RNA is an important marker of acute HEV infection, especially during early stages before the antibody response becomes evident [9]. However, until now, viral RNA has not been detected (in the representative sample) in Lithuanian pigs and wild ungulates such as wild boar, roe deer, red deer and moose. Thus, we aimed to gain insight through molecular investigation into HEV in these species as they are frequently used for human consumption. Furthermore, the availability of the generated HEV sequences may serve as a basis for interdisciplinary studies comparing human isolates to identify transmission interactions between animal and human hosts [10].

\section{Methods}

The sample set for the study comprised 470 pig serum samples that had been collected randomly from farms by veterinarians within the framework of an official infectious disease surveillance program and $626(\mathrm{n}=320$ liver and $\mathrm{n}=306$ serum) samples from wild boar (Sus scrofa) $(\mathrm{n}=505)$, roe deer (Capreolus capreolus) $(\mathrm{n}=93)$, red deer (Cervus elaphus) $(\mathrm{n}=15)$ and moose (Alces alces) $(\mathrm{n}=13)$ that were hunted in 212 locations of Lithuania during the hunting seasons from 2014 to 2016.

Blood samples obtained from the wildlife were gathered from the heart or thoracic cavity into sterile plastic tubes. The serum was separated from the cellular elements by centrifuging the coagulated blood for $10 \mathrm{~min}$ at $2000 \times g$. The extracted serum was stored at $-20^{\circ} \mathrm{C}$ until further analysis. During the dressing of the carcasses, small pieces of hepatic tissues were also taken and stored at $-20{ }^{\circ} \mathrm{C}$ prior to further analysis.

\section{HEV RNA extraction and RT-PCR}

Viral RNA was isolated from serum or liver samples with the Gene JET RNA Purification Kit (Thermo Fisher
Scientific) according to the manufacturer's recommendations. The extracted RNA was analyzed by nested reverse transcription polymerase chain reaction (RT-nPCR) using two HEV-specific sets of primers targeting the ORF1 and ORF2 fragments of the HEV genome (Table 1). The first amplification round was run in $25 \mu \mathrm{L}$ of reaction mix containing $2.5 \mu \mathrm{L}$ of extracted RNA, $12.5 \mu \mathrm{L}$ of Dream Taq Green PCR Master mix (Thermo Fisher Scientific), $1 \mu \mathrm{L}$ of the forward primer HEV-s (or 3156F), $1 \mu \mathrm{L}$ of the reverse primer HEV-as (or 3157R), $0.3 \mu \mathrm{L}$ of RevertAid Reverse Transcriptase (Thermo Fisher Scientific), $0.13 \mu \mathrm{L}$ of RiboLock RNase Inhibitor (Thermo Fisher Scientific) and $7.12 \mu \mathrm{L}$ of nuclease-free water (Thermo Fisher Scientific). The cycling conditions were: $42{ }^{\circ} \mathrm{C}$ for $30 \mathrm{~min}$, initial denaturation at $95{ }^{\circ} \mathrm{C}$ for $5 \mathrm{~min}$ followed by 40 cycles of denaturation at $94{ }^{\circ} \mathrm{C}$ for $30 \mathrm{~s}$ (or $1 \mathrm{~min}$ if ORF2 primers were used), annealing at $50{ }^{\circ} \mathrm{C}$ for $30 \mathrm{~s}$ (or $60{ }^{\circ} \mathrm{C}$ for $1 \mathrm{~min}$ if ORF2 primers were used) and elongation at $72{ }^{\circ} \mathrm{C}$ for $45 \mathrm{~s}$ (or $1 \mathrm{~min}$ if ORF2 primers were used), followed by a final elongation at $72{ }^{\circ} \mathrm{C}$ for $10 \mathrm{~min}$.

Next, $2.5 \mu \mathrm{L}$ of the product of the first amplification round was transferred to a new PCR mix containing $12.5 \mu \mathrm{L}$ of Dream Taq Green PCR Master mix (Thermo Fisher Scientific), $1 \mu \mathrm{L}$ of the forward primer HEV-fn (or 3158Fn), $1 \mu \mathrm{L}$ of the reverse primer HEV-rn (or 3159Rn) and $8 \mu \mathrm{L}$ of nuclease-free water (Thermo Fisher Scientific). The second-round cycling conditions were identical to those of the first except that the cycle at $42{ }^{\circ} \mathrm{C}$ for $30 \mathrm{~min}$ was not required and the annealing temperature of $50{ }^{\circ} \mathrm{C}$ was maintained for $30 \mathrm{~s}$ (or $55^{\circ} \mathrm{C}$ for $1 \mathrm{~min}$ if ORF2 primers were used). All reactions were performed in a Mastercycler personal thermocycler (Eppendorf, Hamburg, Germany). The RT-nPCR products were separated on ethidium bromide-stained $1.8 \%$ agarose gels and visualized by UV light.

To minimize carryover, different parts of the process were physically separated from one another (in entirely separate working areas). A PCR hood and aerosol-barrier

\section{Table 1 Primer sets used in this study}

\begin{tabular}{|c|c|c|c|c|}
\hline Primer designation & Sequence $\left(5^{\prime} \rightarrow 3^{\prime}\right)$ & Step & Product length (bp) & Target region \\
\hline HEV-s & TCGCGCATCACMTTYTTCCARAA & \multirow[t]{2}{*}{ RT-PCR } & \multirow[t]{2}{*}{469} & \multirow[t]{4}{*}{ ORF1 } \\
\hline HEV-as & GCCATGTTCCAGACDGTRTTCCA & & & \\
\hline HEV-fn & TGTTGCCCTGTTTGGCCCCTGGTTTAG & \multirow{2}{*}{$\begin{array}{l}\text { Nested } \\
\text { RT-PCR }\end{array}$} & \multirow[t]{2}{*}{254} & \\
\hline HEV-rn & CCAGGCTCACCRGARTGYTTCTTCCA & & & \\
\hline $3156 \mathrm{~F}$ & AATTATGCYCAGTAYCGRGTTG & \multirow[t]{2}{*}{ RT-PCR } & \multirow[t]{2}{*}{731} & \multirow[t]{4}{*}{ ORF2 } \\
\hline $3157 R$ & CCCTTRTCYTGCTGMGCATTCTC & & & \\
\hline 3158Fn & GTWATGCTYTGCATWCATGGCT & \multirow{2}{*}{$\begin{array}{l}\text { Nested } \\
\text { RT-PCR }\end{array}$} & \multirow[t]{2}{*}{348} & \\
\hline $3159 R n$ & AGCCGACGAAATCAATTCTGTC & & & \\
\hline
\end{tabular}


tips were used for the assembly of all reactions to avoid contamination. In every step, control reactions with no template were performed to check for contamination.

\section{Statistical analyses}

Statistical analysis was conducted using the SPSS for Windows 15 statistics package (SPSS Inc., Chicago, IL, USA). The results were significant when $\mathrm{P}<0.05$. The descriptive data are presented as percentages. Fisher's exact test was used to test for differences in prevalence of HEV and different target regions. HEV prevalence was calculated in pigs and wild animal species for the ORF1 and ORF2 sequences with 95\% confidence intervals.

\section{Sequencing and phylogenetic analysis}

The HEV-positive ORF2 RT-nPCR products were excised from the agarose gel, purified with a GeneJET PCR Purification kit (Thermo Fisher Scientific) and sequenced in both directions using the BigDye Terminator Cycle Sequencing kit v3.1 (Applied Biosystems) and the $3130 \times$ Genetic Analyzer (Applied Biosystems). The sequences of both strands of the ORF2 PCR products were determined using the same primer set and identical cycling conditions as the nested PCR amplification. The sequences were submitted to GenBank.

The obtained ORF2 sequences (Accession Numbers MG739304-MG739318) were compared with the reference set of the selected sequences from GenBank, representing a full range of genetic diversity and geographic locations of the HEV genotype- 3 . The sequences were aligned using Clustal W software from MegAlign (Lasergene software package, DNASTAR Inc, Madison, USA). Bootstrap values were calculated using CLC Gene Free Workbench software, with bootstrap values based on 100 replicates (v4.0.01, CLC bio A/S, Aarhus, Denmark). Bootstrap values greater than $70 \%$ were considered to provide significant evidence for phylogenetic grouping.

\section{Results}

The detailed HEV RNA results targeting different parts of the HEV genome are summarized in Table 2.

In total, 155 of $470(32.98 \%, 95 \%$ CI $28.88-37.35)$ and 106 of 470 (22.55\%, 95\% CI 19.01-26.55) domestic pig samples were positive for HEV RNA using RT-nPCR based on ORF1 and ORF2, respectively. The difference in positive detection rates between ORF1 and ORF2 was highly significant $(\mathrm{P}=0.0004)$.

In wild animal species, $25.94 \%$ (95\% CI $22.31-29.93$ ) of wild boar samples, $22.58 \%$ of roe deer (95\% CI $15.27-$ 32.07) samples, $6.67 \%$ (95\% CI 1.19-29.82) of red deer samples and 7.69\% (95\% CI 1.37-33.31) of moose samples were positive for HEV RNA using primers targeting ORF1. Viral RNA was detected in $17.03 \%$ (95\% CI
14.00-20.55) of wild boar samples and $12.90 \%$ (95\% CI 7.54-21.21) of roe deer samples targeting ORF2, while no HEV RNA was found in red deer or moose samples. Statistically significant differences in the proportion of the prevalence (\%) detected by targeting the ORF1 and ORF2 fragments were observed for all investigated wild animal species except for roe deer.

Samples from different hunting sites and pig farms were sequenced and analyzed to determine the HEV subtypes within different Lithuanian regions and hosts. Phylogenetic analyses based on a 348-nucleotide-long HEV ORF2 region showed that all obtained sequences detected in Lithuanian domestic pigs and wildlife belonged to genotype 3 (Fig. 1). Further subtyping was performed by comparing the obtained sequences with reference sequences representing the $3 \mathrm{a}, 3 \mathrm{~b}, 3 \mathrm{c}, 3 \mathrm{~h}, 3 \mathrm{i}, 3 \mathrm{j}$ subtypes of one major clade and the $3 \mathrm{e}, 3 \mathrm{f}, 3 \mathrm{~g}$ subtypes of another major clade. The sequences identified in this study from pigs, wild boars and roe deer clustered within the $3 \mathrm{i}$ subtype reference sequences from the GenBank database, showing a homology of $88 \%$ (ranging from 86.8 to $88.9 \%$ ). The 13 sequences from pigs, wild boars and roe deer clustered separately within subtype $3 \mathrm{i}$, showing a mean homology of $96.3 \%$ (ranging from 96.3 to 100\%). Two sequences from different pig farms clustered within subtype 3f sequences and revealed $85.3 \%$ (ranging from 71.6 to $99 \%$ ) identity to reference strains of this HEV subtype. One HEV wild boar sequence clustered between subtypes $3 \mathrm{i}$ and $3 \mathrm{~h}$ ORF2 reference sequences and exhibited $85.6-92.1 \%$ identity to subtype $3 \mathrm{i}$ and $87.6-86.4 \%$ to subtype $3 \mathrm{~h}$ sequences.

\section{Discussion}

The presence of HEV in food products derived from natural reservoirs of zoonotic HEV or food (fruits, vegetables, shellfish) that is contaminated by surface and irrigation water raises concerns for public health and food safety worldwide [11]. Autochthonous human HEV infections in industrialized countries (due to genotypes 3 and 4 ) are increasingly reported and are linked to zoonotic transmission, mainly through the consumption of contaminated meat and offal from pigs, Eurasian wild boar and deer that have been deemed to be plausible reservoirs for HEV [12]. Moreover, there is a category of meat from non-domesticated animals (game meat) that are hunted and slaughtered mostly for private consumption, but which can also be found in markets or restaurants. Although game meat represents only a small portion of the European market, its popularity as a luxury food source is growing worldwide. Wild boar and roe deer are the most common sources of game meat in Europe, including Lithuania, and have the largest harvest numbers $[12,13]$. In addition, hunting, which is another 


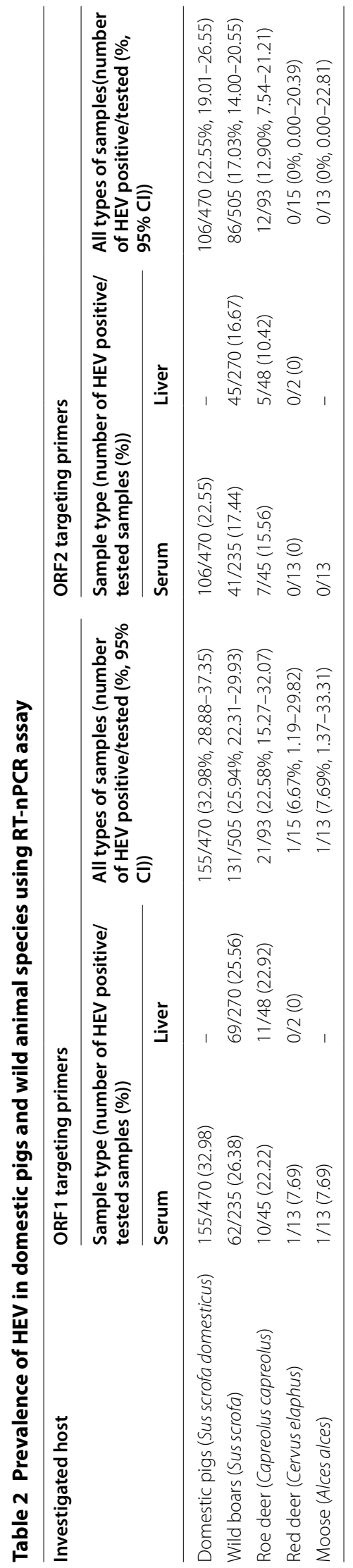




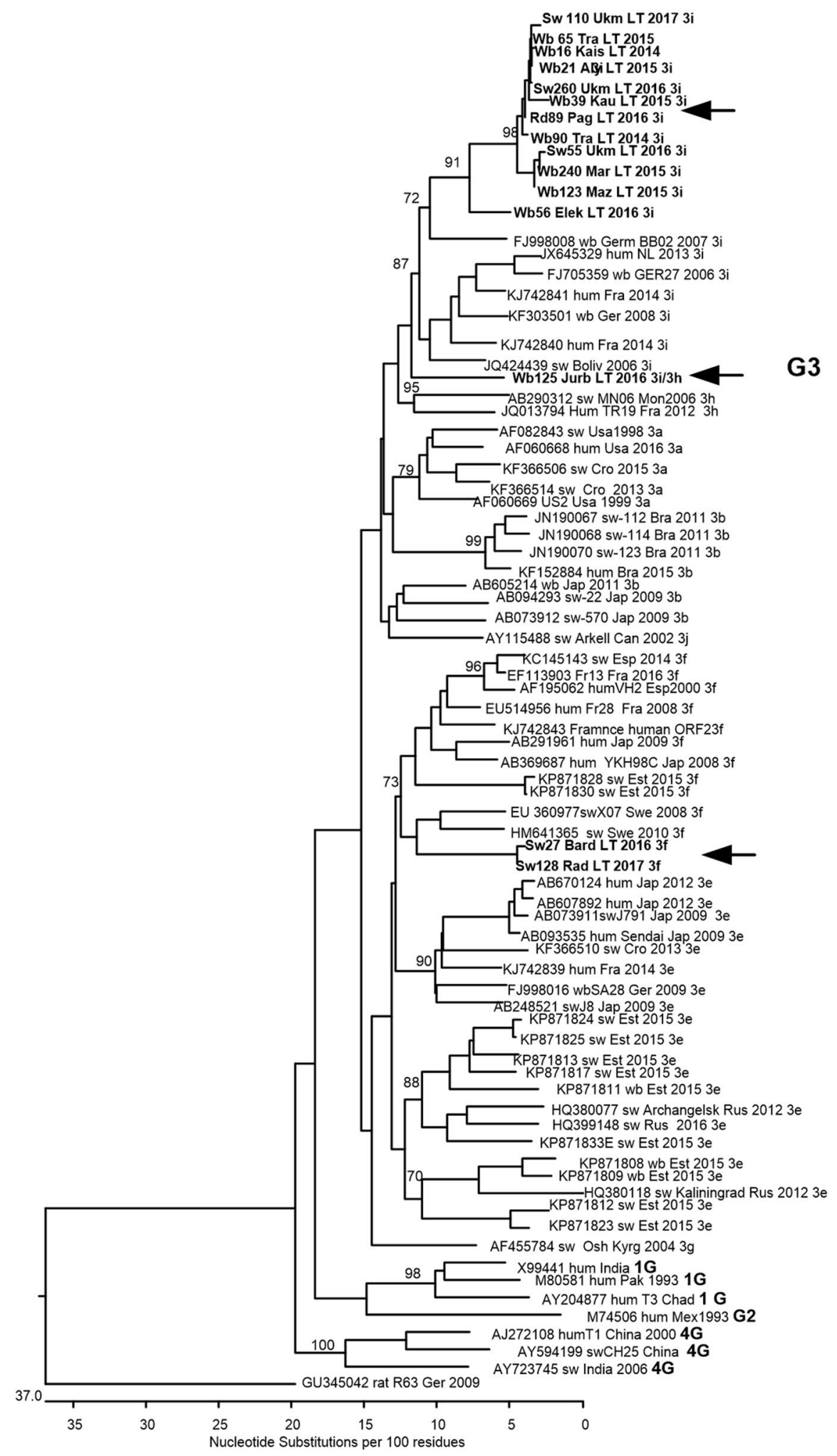

Fig. 1 Phylogenetic analysis of Lithuanian HEV ORF2 sequences. Clustal W algorithm was used for sequence alignment. Numbers adjacent to main branches indicate bootstrap values for different genetic subtypes within HEV genotype3. The reference sequences are marked as follows: GenBank Accession Number, host and name of sequence, country (up to three letter abbreviations), year, subtype. The analysis involved 80-nucleotide partial HEV ORF2 sequences. Only bootstrap values > 70\% are indicated. The sequences determined in this study (Accession Numbers MG739304MG739318) are indicated in bold and with arrows 
recognized risk factor for zoonotic HEV transmission, is very common in Lithuania, with approximately 32624 wild boars and 23828 roe deer killed during the 20162017 hunting season [14]. Thus, the consumption of game meats and offal that may harbor HEV is as risky as eating pork [15].

To date, the detection of HEV is mainly carried out through qualitative or quantitative PCR. Extraction methods and detection protocols can vary significantly, and no gold standard approach has yet been defined for HEV diagnosis. The choice of primers used in RT-PCR assays varies from laboratory to laboratory. The differences in the sensitivity and specificity of various primers often lead to difficulties in comparing results from various studies. Therefore, caution must be taken when interpreting the results. It is known that standard RT-PCR is a sensitive technique, but its sensitivity can be markedly increased by performing nested RT-PCR. The nested strategy increases the specificity of RNA amplification by reducing the background due to non-specific amplification of RNA. Thus, for the direct screening of viral nucleic acids in samples and the ability to use the subsequent positive samples for genotyping, two different PCR assays were applied in this study. For the subtyping of $\mathrm{HEV}$, we needed sequences in the ORF2 region that were 348 bp long. Many real-time RT-PCR products of ORF1, ORF2, and ORF3 are only 76-100 bp in length, which is not long enough for the molecular characterization of prevalent HEV strains.

Domestic pigs had a higher prevalence of HEV (22.55$32.97 \%$ ) than wild ungulates. A possible reason is that the frequent direct contact among infected pigs reared in confined spaces may enhance the spread of HEV. Pigs housed in the same pen are exposed to the saliva, nasal secretions, urine, and feces of multiple pen mates repeatedly each day. Thus, the pig-farming environment may foster the spread of HEV among pigs compared to the environment of free ranging wild ungulates. The HEV RNA prevalence estimated in domestic pigs in the present study remains within the range found in other countries, such as Croatia (24.5\%, [16]) and the USA (35\%, [17]). Crossan et al. [18] reported HEV RNA in 44.4\% of pig serum samples in Scotland, and Di Bartolo et al. [19] detected a viral prevalence of $64.6 \%$ in pigs in Italy, whereas Jori et al. [20] detected HEV RNA in only $8.3 \%$ of tested pig samples. The conducted studies have revealed that different viral prevalence exists among countries. This may reflect different infection dynamics related to farm-specific risk factors, such as farming scale, farming practices, biosecurity measures, and seasonal influence. [21].

The viral RNA prevalence in wild boars, roe deer, red deer and moose was $17.03-25.94 \%, 12.90-22.58 \%$,
$0-6.67 \%$, and $0-7.69 \%$, respectively. Despite the high densities of both wild boar and deer in Lithuania, a slightly lower HEV prevalence was observed in cervids (roe deer, red deer, moose) compared to that in wild boars, hinting towards interspecies transmission. Evidence suggests that deer may contract HEV from wild boars in cases where both species share the same habitat [12].

Other studies have identified HEV in 4.2\% (24/566), $7.5 \%(8 / 106)$ and $12.3 \%$ of tested wild boars in Japan [22], the Netherlands [23] and Croatia [16], respectively. Our results agree with those reported by Mesquita et al. [24], where HEV RNA was detected in 25\% (20/80) of the liver samples obtained from wild boars in Portugal. In contrast, the results from most studies of viral RNA prevalence varied widely even within the same country; HEV detection rates of $14.9 \%(22 / 148,[10])$ and $68.2 \%(90 / 132,[25])$ were found in wild boars in Germany, and 25\% (22/88, $[26])$ and $0 \%(0 / 77,[27])$ in Italy. Hence, the RNA detection method is crucial [19]. In fact, our results confirm different sensitivity with different targeted open reading frames, suggesting that the use of several RT-nPCR protocols may increase the sensitivity of HEV RNA detection [28]. The proportion of HEV RNA-positive samples for both open reading frames in this study did not significantly differ except between roe deer $(22.58 \%$ vs. $12.90 \%$, $\mathrm{P}=0.084)$. However, the sensitivity of RT-PCR assays can vary widely, depending on target regions and HEV genotypes. Furthermore, sensitivity results might be affected by the quality of the RNA extraction procedure [29].

The prevalence of HEV infection among wild cervids has not yet been thoroughly investigated, and data are still inconsistent [3]. In Germany [30], 6.4\% (5/78) of roe deer were positive for viral RNA, while an absence of HEV RNA was reported in the Netherlands (0/8) [23] and Sweden $(0 / 29,0 / 27)$ [31]. Our study results (ranging from 12.90 to $22.58 \%$ depending on the ORF fragment) are partially consistent with those of Forgach et al. [32], who found that $22 \%$ of roe deer (Capreolus capreolus) were positive for HEV RNA in Hungary.

In this study, 6.67 and $7.69 \%$ of red deer and moose samples were positive for HEV ORF1. The positive result could be caused by specific or unspecific amplification of ORF1 fragment and it is noted these animals HEV strains were not successful sequenced. Moreover, none of the 15 red deer or 13 moose samples were positive for the HEV ORF2 fragment. These results might be affected by a relatively small sample size. The reason for the absence of positive cases might be divergent HEV types that could not be detected by the assay used in this study [31]. Similar findings have been recently reported in Germany, where HEV was detected in $2.0-6.6 \%$ of red deer samples [33]. A higher HEV prevalence was noticed in red 
deer populations in Hungary (10\%, [32]), Italy (11\%, [34]) and the Netherlands $(15 \%,[23])$. There is a lack of surveillance data regarding the prevalence of HEV RNA in moose, which makes it difficult to compare prevalence trends. In another study, $15 \%$ of moose samples collected in 2012-2013 in Sweden were positive for viral RNA [35]. Similar results were reported by Roth et al. [31], who detected HEV in 11\% (10/66) and 15\% (7/11) of Swedish moose samples from 2012 to 2015.

Phylogenetic analyses of partial ORF2 HEV sequences have shown that several genetic subtypes of the HEV genotype 3 are present in Lithuanian pigs and wildlife [36]. The comparison of sequences obtained from wild boar, pig and roe deer samples showed a high degree of homology and clustered within subtype $3 i$ reference sequences. This suggests that only the subtype $3 i$ of HEV genotype 3 is circulating in Lithuanian pigs and wildlife. However, the clustering of the wild boar sequence (Wb125 Jurb LT $20163 \mathrm{i} / 3 \mathrm{~h}$ ) between the $3 \mathrm{i}$ and $3 \mathrm{~h}$ subtype sequences show that the wild boar population in Lithuania can also harbor additional subtypes of the HEV 3 genotype. This sequence showed 13.5-14\% nucleotide variation compared to $3 \mathrm{i}$ subtype reference strains and $15-16 \%$ variation compared to subtype $3 \mathrm{~h}$.

The HEV 3i subtype has been detected in Austria, Germany, France, Argentina, Bolivia, and Uruguay in various hosts, including humans [25, 36, 37], wild boars [10, $25]$ and domestic pigs [37, 38]. The ORF2 nucleotide sequence obtained in this study from roe deer (Rd89 Pag LT 2016 3i) shows that the HEV 3i subtype can be found in this species as well. Until recently, the $3 \mathrm{i}$ subtype had only been detected in wild boars in Germany, while in Austria and Argentina it has also been detected in humans [39]. The German wild boar strains of HEV sequences wbGER27 and BB02 were fully sequenced and used as reference HEV 3i subtype sequences $[10,25]$ in this study.

The sequences obtained from pig farms located in two different counties of Lithuania clustered with HEV strains from Estonia [40], Sweden [41], France [42], Croatia [16], and Hungary [32], and all of them were of the HEV 3f subtype. Interestingly, only one HEV $3 f$ strain was isolated from wild boars, while all other $3 \mathrm{f}$ strains were isolated from humans to pigs. The presence of the HEV 3f subtype in Lithuanian pig farms may be due to import of animals from other parts of the EU as HEV strains isolated from wild boars and pigs in the neighboring regions of Estonia and the Kaliningrad district of the Russian Federation, have belonged to the 3e subtype [40].

\section{Conclusions}

This study shows that pigs, wild boars, roe deer, red deer and moose in Lithuania may be infected with HEV. This calls for an increased public awareness of the zoonotic risk of HEV infection through food consumption or contact with infected animal populations.

\section{Authors' contributions}

AS designed and coordinated the study. JB, US, DZ, DR, MS and JG collected and analysed the samples. AS, US and JG drafted the manuscript. US, JZ and JB performed the literature review. VJ and JG conducted the statistical analyses. All authors read and approved the final manuscript.

\section{Author details}

${ }^{1}$ Department of Anatomy and Physiology, Faculty of Veterinary Medicine, Lithuanian University of Health Sciences, Tilzes str. 18, Kaunas, Lithuania.

${ }^{2}$ National Food and Veterinary Risk Assessment Institute, J. Kairiukscio str. 10, Vilnius, Lithuania. ${ }^{3}$ Department of Animal Breeding and Nutrition, Faculty of Animal Husbandry Technology, Lithuanian University of Health Sciences, Tilzes str. 18, Kaunas, Lithuania. ${ }^{4}$ Faculty of Medicine, Lithuanian University of Health Sciences, A. Mickeviciaus str. 9, Kaunas, Lithuania. ${ }^{5}$ Faculty of Veterinary Medicine, Institute of Microbiology and Virology, Lithuanian University of Health Sciences, Tilzes str. 18, Kaunas, Lithuania.

\section{Acknowledgements}

The authors are profoundly grateful to the Lithuanian farmers and veterinarians who kindly agreed to help us in this study and also to the hunters who provided wild animal samples.

\section{Competing interests}

The authors declare that they have no competing interests.

\section{Availability of data and materials}

The datasets used and/or analysed during the current study are available from the corresponding author on reasonable request.

Consent for publication

Not applicable.

Ethics approval and consent to participate

Ethical approval was not required as all samples were collected within the framework of an official infectious disease surveillance program or from already hunted animals.

\section{Funding}

This study was supported by the Science Foundation of the Lithuanian University of Health Sciences.

\section{Publisher's Note}

Springer Nature remains neutral with regard to jurisdictional claims in published maps and institutional affiliations.

Received: 2 November 2017 Accepted: 15 February 2018

Published online: 23 February 2018

References

1. Hara Y, Terada Y, Yonemitsu K, Shimoda H, Noguchi K, Maeda K. High prevalence of hepatitis E virus in wild boar (Sus scrofa) in Yamaguchi Prefecture, Japan. J Wildl Dis. 2014;50:378-83.

2. Dalton HR. Hepatitis E: the "new kid on the block" or an old friend? Transfus Med Hemother. 2014;41:6-9.

3. Serracca L, Battistini R, Rossini I, Mignone W, Peletto S, Boin C, et al. Molecular investigation on the presence of hepatitis $E$ virus (HEV) in wild game in North-Western Italy. Food Environ Virol. 2015;7:206-12.

4. Tei S, Kitajimam N, Takahashim K, Mishirom S. Zoonotic transmission of hepatitis E virus from deer to human beings. Lancet. 2003;362:371-3.

5. Yazaki Y, Mizuo H, Takahasi M, Nishizawa T, Sasaki N, Goatnada Y, et al. Sporadic acute hepatitis $E$ in Hokkaido, Japan, may be food-borne, as suggested by the presence of hepatitis E virus in pig liver as food. J Gen Virol. 2003;84:2351-7. 
6. Li TC, Chijiwa K, Sera N, Ishibashi T, Etoh Y, Shinohara Y, et al. Hepatitis E virus transmission from wild boar meat. Emerg Infect Dis. 2005:11:1958-60.

7. Riveiro-Barciela M, Rodríguez-Frías F, Buti M. Hepatitis E virus: new faces of an old infection. Ann Hepatol. 2012;12:861-70.

8. Renou C, Roque Afonso A, Pavio N. Foodborne transmission of hepatitis E virus from raw pork liver sausage, France. Emerg Infect Dis. 2014;20:1945-7.

9. La Rosa G, Fratini M, Muscillo M, laconelli M, Taffon S, Equestre M, et al. Molecular characterisation of human hepatitis E virus from Italy: comparative analysis of five reverse transcription-PCR assays. Virol J. 2014. https://doi.org/10.1186/1743-422x-11-72.

10. Schielke A, Sachs K, Lierz M, Appel B, Jansen A, Johne R. Detection of hepatitis $E$ virus in wild boars of rural and urban regions in Germany and whole genome characterization of an endemic strain. Virol J. 2009. https://doi.org/10.1186/1743-422x-6-58.

11. Doceul V, Bagdassarian E, Demange A, Pavio N. Zoonotic hepatitis E virus: classification, animal reservoirs and transmission routes. Viruses. 2016. https://doi.org/10.3390/v8100270.

12. Boadella M. Hepatitis E in wild ungulates: a review. Small Rumin Res, 2015;128:64-71.

13. Schulp CJE, Thuiller W, Verburg PH. Wild food in Europe: a synthesis of knowledge and data of terrestrial wild food as an ecosystem service. Ecol Econ. 2014;105:292-305.

14. Ministry of environment of the Republic of Lithuania official reports (ME), 2016-2017. http://www.am.It/NI/index.php\#a/18446. Accessed July 15 2017.

15. Lhomme S, Top S, Bertagnoli S, Dubois M, Guerin J, Izopet J. Wildlife reservoir for hepatitis E virus, Southwestern France. Emerg Infect Dis. 2015;21:1224-6.

16. Prpić J, Černi S, Škorić D, Keros T, Brnić D, Cvetnić Z, et al. Distribution and molecular characterization of hepatitis $E$ virus in domestic animals and wildlife in Croatia. Food Environ Virol. 2015:7:195-205.

17. Huang FF, Haqshenas G, Guenette DK, Halbur PG, Schommer SK, Pierson FW, et al. Detection by reverse transcription-PCR and genetic characterization of field isolates of swine hepatitis E virus from pigs in different geographic regions of the United States. J Clin Microbiol. 2002;40:1326-32.

18. Crossan C, Grierson S, Thomson J, Ward A, Nunez-Garcia J, Banks M, et al. Prevalence of hepatitis E virus in slaughter-age pigs in Scotland. Epidemiol Infect. 2015;143:2237-40

19. Di Bartolo I, Ponterio E, Castellini L, Ostanello F, Ruggeri FM. Viral and antibody HEV prevalence in swine at slaughterhouse in Italy. Vet Microbiol. 2011;149:330-8.

20. Jori F, Laval M, Maestrini O, Casabianca F, Charrier F, Pavio N. Assessment of domestic pigs, wild boars and feral hybrid pigs as reservoirs of hepatitis E virus in Corsica, France. Viruses. 2016. https://doi.org/10.3390/v8080236.

21. Salines M, Andraud M, Rose N. From the epidemiology of hepatitis E virus (HEV) within the swine reservoir to public health risk mitigation strategies: a comprehensive review. Vet Res. 2017. https://doi.org/10.1186/ s13567-017-0436-3.

22. Takahashi M, Nishizawa T, Nagashima S, Jirintai S, Kawakami M, Sonoda $Y$, et al. Molecular characterization of a novel hepatitis E virus (HEV) strain obtained from a wild boar in Japan that is highly divergent from the previously recognized HEV strains. Virus Res. 2014;180:59-69.

23. Rutjes SA, Lodder-Verschoor F, Lodder WJ, Giessen J, Reesink H, Bouwknegt $\mathrm{M}$, et al. Seroprevalence and molecular detection of hepatitis E virus in wild boar and red deer in the Netherlands. J Virol Methods. 2010;168:197-206.
24. Mesquita JR, Oliveira RM, Coelho C, Vieira-Pinto M, Nascimento MS. Hepatitis E virus in sylvatic and captive wild boar from Portugal. Transbound Emerg Dis. 2016;63:574-8.

25. Adlhoch C, Wolf A, Meisel H, Kaiser M, Ellerbrok H, Pauli G. High HEV 225 presence in four different wild boar populations in East and West Germany. Vet Microbiol. 2009;139:270-8.

26. Martelli F, Caprioli A, Zengarini M, Marata A, Fiegna C, Di Bartolo I, et al. Detection of hepatitis E virus (HEV) in a demographic managed wild boar (Sus scrofa scrofa) population in Italy. Vet Microbiol. 2008;126:74-81.

27. Martinelli N, Pavoni E, Filogari D, Ferrari N, Chiari M, Canelli E, et al. Hepatitis E virus in wild boar in the Central Northern part of Italy. Transbound Emerg Dis. 2015;62:217-22.

28. Vasickova P, Psikal I, Widen F, Smitalova R, Bendova J, Pavlik I, et al. Detection and genetic characterisation of hepatitis E virus in Czech pig production herds. Res Vet Sci. 2009;87:143-8.

29. Mokhtari C, Marchadier E, Haïm-Boukobza S, Jeblaoui A, Tessé S, Savary J, et al. Comparison of real-time RT-PCR assays for hepatitis E virus RNA detection. J Clin Virol. 2013;58:36-40

30. Anheyer-Behmenburg HE, Szabo K, Schotte U, Binder A, Klein G, Johne R. Hepatitis $E$ virus in wild boars and spillover infection in red and roe deer, Germany, 2013-2015. Emerg Infect Dis. 2017;23:130-3.

31. Roth A, Lin J, Magnius L, Karlsson M, Belák S, Widén F, et al. Markers for ongoing or previous hepatitis $\mathrm{E}$ virus infection are as common in wild ungulates as in humans in Sweden. Viruses. 2016. https://doi. org/10.3390/v8090259.

32. Forgách P, Nowotny N, Erdélyi K, Boncz A, Zentai J, Szucs G, et al. Detection of hepatitis $E$ virus in samples of animal origin collected in Hungary. Vet Microbiol. 2010;143:106-16.

33. Neumann S, HackI SS, Piepenschneider M, Vina-Rodriguez A, Dremsek P, Ulrich RG, et al. Serologic and molecular survey of hepatitis E virus in German deer populations. J Wildl Dis. 2015;52:106-13.

34. Di Bartolo I, Ponterio E, Angeloni G, Morandi F, Ostanello F, Nicoloso S, et al. Presence of hepatitis E virus in a red deer (Cervus elaphus) population in Central Italy. Transbound Emerg Dis. 2017;64:137-43.

35. Lin J, Karlsson M, Olofson AS, Belák S, Malmsten J, Dalin AM, et al. High prevalence of hepatitis E virus in Swedish moose-a phylogenetic characterization and comparison of the virus from different regions. PLoS ONE. 2015. https://doi.org/10.1371/journal.pone.0122102.

36. Lu L, Li C, Hagedorn CH. Phylogenetic analysis of global hepatitis E virus sequences: genetic diversity, subtypes and zoonosis. Rev Med Virol. 2006;16:5-36

37. Mirazo S, Mainardi V, Ramos N, Gerona S, Rocca A, Arbiza J. Indigenous hepatitis E virus genotype 1 infection, Uruguay. Emerg Infect Dis. 2014:20:171-3.

38. Purdy MA. Evolution of the hepatitis E virus polyproline region: order from disorder. J Virol. 2012;86:10186-93.

39. Vina-Rodriguez A, Schlosser J, Becher D, Kaden V, Groschup MH, Eiden M. Hepatitis E virus genotype 3 diversity: phylogenetic analysis and presence of subtype 3b in wild boar in Europe. Viruses. 2015;7:2704-26.

40. Ivanova A, Tefanova V, Reshetnjak I, Kuznetsova T, Geller J, Lundkvist $\AA$, et al. Hepatitis E virus in domestic pigs, wild boars, pig farm workers, and hunters in Estonia. Food Environ Virol. 2015;7:403-12.

41. Widén F, Sundqvist L, Matyi-Toth A, Metreveli G, Belák S, Hallgren G, et al. Molecular epidemiology of hepatitis $E$ virus in humans, pigs and wild boars in Sweden. Epidemiol Infect. 2011;139:361-71.

42. Colson P, Borentain P, Queyriaux B, Kaba M, Moal V, Gallian P, et al. Pig liver sausage as a source of hepatitis $E$ virus transmission to humans. J Infect Dis. 2010;202:825-34 